\title{
A queixa escolar na perspectiva de educadores da Educação Especial
}

\author{
Solange Pereira Marques Rossato \\ Nilza Sanches Tessaro Leonardo
}

\begin{abstract}
Resumo
O presente estudo trata da queixa escolar no que se refere às concepções de educadores sobre as dificuldades de aprendizagem de alunos com deficiência intelectual que frequentam escolas especiais (APAEs), com a finalidade de verificar se existe a queixa escolar nestas escolas, e caso exista, que concepções a permeiam, quais as possíveis causas atribuídas a esse fato imbricadas no ensino de tais alunos. Foram entrevistados 21 educadores pertencentes a três escolas especiais localizadas no Estado do Paraná. Os resultados apontam um processo de naturalização da queixa escolar, com a compreensão de que esses alunos têm deficiência e não dificuldades de aprendizagem enquanto incapacidade para o aprendizado dos conhecimentos científicos, desconsiderando a inadequação das mediações, a má qualidade do ensino e a rede de relações envolvida. Os educadores geralmente fundamentam suas visões em um paradigma biologicista, reduzindo o desenvolvimento a um processo natural e inato.
\end{abstract}

Palavras-chave: Dificuldades escolares, psicologia histórico-cultural, educação especial.

\section{School complaint from the perspective of Special Education teachers}

\begin{abstract}
In this study we examine school complaint from the perspective of Professional in Education when referring to the learning difficulties of students with intellectual disabilities who attend special schools (APAEs). We propose to investigate whether there is school complaints in these schools, and if so, what are the conceptions that permeate it, what are the causes attributed to this fact that intertwined in teaching such students. We interviewed 21 teachers from three special schools in the State of Paraná. The results show a naturalization process of learning difficulties, with the understanding that these students have disabilities and learning difficulties as inability to learn the scientific knowledge, disregarding the inadequacy of mediations, the poor quality of teaching and the network of relationships involved. Educators often base their views on a biological paradigm, reducing the development to a natural and innate process.
\end{abstract}

Keywords: Learning disabilities, historical-cultural psychology, special education.

\section{La queja escolar bajo perspectiva de educadores de Educación Especial}

\section{Resumen}

El presente estudio trata de la queja escolar en lo que se refiere a las concepciones de educadores sobre dificultades de aprendizaje de alumnos con deficiencia intelectual que frecuentan escuelas especiales (APAEs). La finalidad fue de verificar si existía queja escolar en estas escuelas, y caso existiera, que concepciones la atraviesan, cuales las posibles causas atribuidas a este hecho entrelazadas en la enseñanza de tales alumnos. Se entrevistaron 21 educadores pertenecientes a tres escuelas especiales localizadas en el Estado de Paraná. Los resultados señalan un proceso de naturalización de la queja escolar, con el entendimiento de que los alumnos tienen discapacidades, y no dificultades de aprendizaje, como incapacidad para aprender conocimientos científicos, desconsiderando la falta de adecuación de mediaciones, la mala calidad de la enseñanza y la red de relaciones involucrada. Los educadores generalmente fundamentan sus visiones en un paradigma biologicista, reduciendo el desarrollo a un proceso natural e innato.

Palabras Clave: Dificultades escolares, Psicología Histórico-Cultural, Educación Especial. 


\section{Introdução}

As relações estabelecidas numa sociedade organizada no modo de produção capitalista e com sustentação nos arcabouços teórico-filosóficos do neoliberalismo, que leva à veiculação de concepções pautadas no sucesso e fracasso por conta de atributos individuais, têm norteado as políticas no âmbito da Educação Escolar (Patto, 1990). Nessa perspectiva, nossa sociedade vem sendo marcada por relações de desigualdade de classes e de exclusão, na medida em que se privilegia uma minoria dominante em detrimento da maioria, que é privada de condições de vida humana dignas. Entre essas inapropriadas condições encontra-se uma educação escolar historicamente marcada pelo fato de nem todos terem acesso a ela e por sua baixa qualidade.

Produto disso é o crescente número de pessoas que compõem os chamados fracassos escolares, a que muitas vezes se agrega uma série de dificuldades e fracassos que são construídos no bojo dessa sociedade, mas explicados como individuais. Por isso, ante a problemática da queixa e do fracasso escolar, não raras vezes os estudos desconsideram as condições históricas, sociais, políticas e econômicas envolvidas no processo de produção de tal problemática (Laplane, 2006; Machado, 1997), interpretando o fenômeno a partir de uma ideia de anormalidade (de que falta algo ao aluno) que permite taxar os alunos de "fracassados", sujeitos "incapazes" ou portadores de problemas psiconeurológicos.

Ao tratar do fracasso escolar, Patto (1990) faz um trabalho de análise crítica de teorias da década de 1980 consideradas ideologizantes. Seus estudos questionavam as explicações de natureza psicologicista e biologicista que definiam o fracasso da escola (o não aprender dos alunos) por meio de avaliações auxiliadas pelo uso extremo de padrões de medida, buscando substituí-las por teorias difundidas a partir da década de 1960 que justificavam o fracasso escolar pela carência afetiva e cultural e colocavam a pobreza como fator determinante.

A autora considera o fracasso escolar uma produção histórico-social da ação humana, resultante de uma sociedade que desvaloriza as condições econômicas e sociais dos alunos empobrecidos da escola pública e se caracteriza por desigualdades sociais e educacionais entre grupos e classes decorrentes da inadequação da escola e de sua má qualidade.

Nesse processo de produção do fracasso escolar solidificam-se naturalizações e vão se criando categorias e modalidades de ensino que preenchem as lacunas do insucesso escolar. Assim, passa a ser aceitável e recomendável que uma criança que não esteja indo bem na escola frequente uma classe ou escola especial, ou mesmo que passe a ser denominada de deficiente, hiperativa, disléxica etc. A partir destas categorizações e segregações educativas, as expectativas de aprendizagem passam a ser muito pequenas, de tal modo que não aprender torna-se algo natural.

Por isso, na compreensão de Saviani (2005), é preciso que façamos uma leitura crítica sobre a educação, de modo a percebermos os elementos culturais que necessitam ser assimilados pelos indivíduos para a sua humanização, e sobre as formas mais adequadas de se concretizar esse objetivo, pois é por meio de um ensino de qualidade que os alunos terão melhores condições de se apropriar da cultura historicamente construída.

Ao se considerar a educação escolar como fundamental para a apropriação da cultura produzida, cabe questionar a educação e, dentro desta, a Educação Especial, discutindo-se as formas e condições de ensino oferecidas às pessoas com deficiência e às que aprendem diferentemente, por nem sempre lhes possibilitarem o aprendizado escolar. Tais condições de ensino podem concentrar nessas pessoas o estigma de fracasso e incapacidade, de maneira a não ser possível à escola cumprir sua função de socialização do conhecimento elaborado e sistematizado.

Laplane (2006) discute que tais práticas vêm ao encontro da organização de nossa sociedade, que responsabiliza o indivíduo pelo seu sucesso ou eventual fracasso. A educação não foge a isso, já que está envolvida nesse processo de construção. Resta saber como ocorrem tais relações no interior da Educação Especial, como o aluno que apresenta dificuldades vem sendo percebido e que concepções e explicações sobre a queixa escolar fundamentam o trabalho dos educadores das escolas especiais.

L. S. Vigotski ${ }^{1}$ (1896-1934), teórico que escreveu em outra época e outra sociedade e liderou a Psicologia Histórico-Cultural, questionou a percepção da deficiência como reduzida à limitação naturalizadamente quantitativa do seu desenvolvimento e defendeu como tese básica acerca da deficiência (que denomina de defectologia) que uma criança cujo desenvolvimento é dificultado pelo seu "defeito" não é menos desenvolvida que as crianças ditas normais, mas, simplesmente, é desenvolvida de outro modo, ou seja, de um modo peculiar.

O autor aponta que não é especificamente a deficiência em seu aspecto biológico, orgânico, que atua por si mesma, e sim o conjunto de relações que o indivíduo estabelece com o outro e com a sociedade por conta de tal deficiência. Assim, para Vygotski (1997), a participação e os papéis sociais atribuídos às pessoas com deficiência são vinculados às percepções deterministas de seu desenvolvimento. Com isso, as consequências sociais do defeito percebido é que decidem o destino da pessoa com deficiência. $\mathrm{O}$ autor fundamenta-se na perspectiva de que a pessoa com deficiência é também detentora de potencialidades e de que, se as devidas condições de aprendizagem (com os recursos especiais) Ihe forem oferecidas, se Ihe oportunizarem adequadamente a apropriação da cultura histórica e socialmente construída, ela terá movimentadas as suas possibilidades de se desenvolver e realizar compensações do "defeito". Defende a perspectiva da pessoa com deficiência com uma visão para além de organicista, de fato materializada nas condições objetivas de vida.

1 Nas leituras realizadas foi possível perceber que Vigotski é grafado de diferentes formas. Então adotaremos essa grafia, salvo em caso de referência e citação. 
Assim, pode-se concluir que o modo como a organização da Educação Especial e do ensino que esta empreende foi sendo constituída ao longo da história ocorreu conforme se organizavam os fatores socioeconômicos determinantes de cada época. Esses fatores delimitavam e delimitam em cada momento o tipo de atendimento, os conceitos e as relações estabelecidas com a deficiência. Deste modo, na queixa escolar, a deficiência precisa ser analisada e compreendida no interior da sociedade que se desenvolve, no desvelar das leis que a produzem e das contradições ideológicas presentes.

Não obstante, embora vivamos sob a égide histórica de um movimento de inclusão escolar, a escola especial ainda se constitui atualmente como o "lugar" da deficiência intelectual, o que nos leva a refletir sobre a educação especial oferecida a essas pessoas e buscar compreendê-la na perspectiva da queixa escolar, ou seja, a partir das dificuldades identificadas pelos educadores no tocante ao rendimento escolar que interferem no processo ensino-aprendizagem. Nesta tessitura, buscamos verificar se existe a produção da queixa escolar na Educação Especial (APAEs - Associação de Pais e Amigos dos Excepcionais) e, caso exista, identificar como os educadores das APAEs a concebem e as possíveis causas a ela atribuídas.

Enfim, buscamos entender se os alunos que frequentam essa modalidade de ensino são vistos como pessoas com capacidade para aprender, desenvolver-se, humanizar-se, e se nas relações de ensino-aprendizagem são assim considerados ou se suas dificuldades são tidas como diretamente relacionadas às suas "limitações/deficiências/ anormalidades/carências", pois entendemos que essa é uma condição necessária para haver investimento em sua aprendizagem.

Considerando essas informações e discussões, este texto se fundamenta na abordagem histórico-cultural, a qual, por sua vez, ampara-se nos fundamentos do Materialismo Histórico-Dialético, que tem como base central a compreensão do homem como um ser social, histórica, cultural e economicamente constituído nas interações que estabelece com a sua realidade social.

\section{Método}

\section{Participantes}

Participaram desta pesquisa vinte e uma educadoras (professoras e coordenadoras) de três escolas especiais APAEs localizadas no interior do Paraná (sete de cada escola), formando os grupos G1, G2 e G3. As idades das participantes variavam entre 29 e 61 anos, sendo que a maioria se encontrava na faixa etária dos 32 aos 40 anos. Quanto ao grau de escolaridade, todas têm curso superior, dezessete educadoras fizeram especialização em Educação Especial e quatro delas fizeram estudos adicionais em deficiência intelectual. Seu tempo de experiência na educação de de- ficientes intelectuais variava entre dois e quarenta anos (a maioria tinha entre cinco e quinze anos de trabalho nesta modalidade de ensino).

\section{Material}

Os materiais utilizados para a realização da pesquisa foram os seguintes: documento de anuência da escola, termo de consentimento livre e esclarecido, ficha de identificação dos participantes, ficha de identificação da instituição, roteiro de entrevista e gravador.

\section{Procedimentos}

Primeiramente procedemos às visitas às APAEs, a fim de pontuar os aspectos fundamentais, objetivos e procedimentos da pesquisa, bem como a importância da participação da escola. Em seguida entregamos à direção o documento de anuência da escola, solicitando a autorização para a construção das informações da presente pesquisa e explicitando que o documento assinado pela direção seria apresentado ao Comitê Permanente de Ética em Pesquisa Envolvendo Seres Humanos da Universidade Estadual de Maringá.

A partir do parecer favorável deste Comitê, realizamos o contato com as participantes da pesquisa na própria escola em que trabalham, a fim de explicar os objetivos e procedimentos a ela concernentes e apresentar o termo de consentimento. Após a anuência das participantes, foi-Ihes entregue a ficha de identificação com o intuito de obter informações de ordem pessoal (idade, sexo, escolaridade, formação) e profissional (experiência profissional, atuação atual), a qual foi por elas preenchida. Em seguida, foi realizada com elas a entrevista, que se apoiou num roteiro, procurando abranger os objetivos inicialmente propostos pela pesquisa.

Destacamos que para a organização das informações obtidas por meio das entrevistas foi utilizada a análise de conteúdo. Segundo Rocha e Deusdará (2005), a análise de conteúdo consiste em captar uma mensagem que está por trás da superfície textual, sendo utilizada para o tratamento de dados com vista a identificar o que está sendo dito a respeito de determinado tema. $\mathrm{Na}$ análise de conteúdo empregou-se, entre as técnicas possíveis, a análise categorial para trabalhar com as informações das entrevistadas. No presente caso, realizamos uma leitura minuciosa, buscando evidenciar os elementos de destaque em cada item proposto no roteiro da entrevista para assim construir as categorias de análise.

A fim de facilitar e possibilitar uma melhor visualização, as informações foram agrupadas em tabelas e, posteriormente, no intuito de compreendê-las e analisá-las dentro da realidade engendrada, no sentido de apreender as determinações constitutivas das relações entre as partes e a totalidade, apoiamo-nos também nos fundamentos teóricos trazidos no referencial bibliográfico deste trabalho. 


\section{Resultados e Discussões}

Para as discussões pretendidas neste texto, primeiramente nos apoiamos no item investigado junto às participantes "Compreensão acerca da queixa escolar", a respeito do qual foi solicitado que expusessem como entendem a queixa no seu cotidiano escolar. A partir daí foram construídas as categorias que se encontram na tabela 1. Em seguida nos ativemos a outro item "Possíveis causas da queixa escolar", em que as participantes falam da origem das dificuldades interferentes no processo de escolarização, o que culminou nas categorias da tabela 2 .

\section{Compreensão dos participantes acerca da queixa escolar}

As informações contidas na tabela 1 revelam que as categorias prevalentes no tocante à compreensão das par- ticipantes sobre a queixa escolar referem-se às seguintes categorias: Não respondeu à questão (33,3\%); dificuldade específica que o aluno tem (18,5\%); O aluno que tem mais dificuldade em assimilar, reter e/ou registrar os conhecimentos, elou em fazer elaborações mais complexas (14,9\%). Além destas, outras categorias com um percentual menor de respostas compuseram a tabela.

Numa análise como um todo, é possível perceber que houve uma significativa variedade nas respostas das participantes - o que pode ser considerado como uma falta de convergência de entendimentos quanto ao que lhes parece representar a queixa escolar, ou ainda que essa expressão não é corriqueiramente utilizada na práxis das instituições em questão, mas sim nas escolas de ensino regular. Por outro lado, pode indicar ainda uma possível naturalização dos problemas evidenciados no seu cotidiano, vistos como algo comum aos alunos atendidos nas suas escolas e não como um fenômeno à parte, diferencial.

Tabela 1. Compreensão dos participantes acerca da queixa escolar.

\begin{tabular}{|c|c|c|c|c|c|c|c|c|}
\hline \multirow[t]{2}{*}{ Categorias } & \multicolumn{2}{|c|}{ G1 } & \multicolumn{2}{|c|}{ G2 } & \multicolumn{2}{|c|}{ G3 } & \multicolumn{2}{|c|}{ Total } \\
\hline & $\mathrm{F}$ & $\%$ & $\mathbf{F}$ & $\%$ & $\mathbf{F}$ & $\%$ & $\mathbf{F}$ & $\%$ \\
\hline 1 - Não respondeu à questão & - & - & 4 & 44.4 & 5 & 62.5 & 9 & 33.3 \\
\hline $\begin{array}{l}2 \text { - Dificuldade específica que o } \\
\text { aluno tem }\end{array}$ & 3 & 30 & 1 & 11.1 & 1 & 12.5 & 5 & 18.5 \\
\hline $\begin{array}{l}\text { 3- O aluno que tem mais dificuldade } \\
\text { em assimilar, reter e/ou registrar } \\
\text { os conhecimentos, e/ou em fazer } \\
\text { elaborações mais complexas }\end{array}$ & 3 & 30 & 1 & 11.1 & - & - & 4 & 14.9 \\
\hline $\begin{array}{l}4 \text { - Quando se trabalha com os } \\
\text { alunos e não se obtêm resultados }\end{array}$ & 2 & 20 & - & - & - & - & 2 & 7.4 \\
\hline $\begin{array}{l}5 \text { - Dificuldade de aprendizagem } \\
\text { decorrente do comportamento } \\
\text { inadequado da criança }\end{array}$ & - & - & 2 & 22.3 & - & - & 2 & 7.4 \\
\hline $\begin{array}{l}6 \text { - Dificuldade de aprendizagem } \\
\text { associada à prática pedagógica }\end{array}$ & - & - & - & - & 2 & 25 & 2 & 7.4 \\
\hline $\begin{array}{l}7 \text { - Dificuldade em se desenvolver } \\
\text { em todas as disciplinas }\end{array}$ & 1 & 10 & - & - & - & - & 1 & 3.7 \\
\hline $\begin{array}{l}8 \quad \text { - Alunos com deficiência } \\
\text { acentuada em que se trabalha com } \\
\text { métodos específicos }\end{array}$ & 1 & 10 & - & - & - & - & 1 & 3.7 \\
\hline $\begin{array}{l}9 \text { - Dificuldade de aprendizagem } \\
\text { em decorrência de uma falha no } \\
\text { processo de escolarização }\end{array}$ & - & - & 1 & 11.1 & - & - & 1 & 3.7 \\
\hline Total & 10 & 100 & 09 & 100 & 8 & 100 & 27 & 100 \\
\hline
\end{tabular}

Nota: As porcentagens foram calculadas a partir do total de respostas referentes às distintas categorias e não a partir do número de participantes. 
Os apontamentos referidos nos levam a pensar, em paralelo, na categoria "Não respondeu à questão" (33,3\%). Este "silenciar-se" diante da queixa pode indicar que as educadoras não têm as ferramentas para compreendê-la, ou mesmo para identificá-la no cotidiano escolar.

Assim, nesta, as educadoras expressaram suas limitações em referir o que entendiam sobre queixa escolar e as dificuldades de aprendizagem. Com isso suas respostas ora vinham para justificar as dificuldades dos seus alunos, ora para falar do lugar da queixa no ensino regular, ora para explicitar sua presença no cotidiano escolar da Educação Especial, mas não corporificada como tal. "[...] Eu acho que é um grupo de assuntos que os profissionais na área fazem comentários sobre isso, né? [...]" (P2/G2). A queixa aparece mais na perspectiva de um relato comum do cotidiano escolar, como algo mais natural e não com uma conotação propriamente de problema, ou de algo que se apresente para além do esperado e surpreenda. São lamentos que ressoam em seu cotidiano, mas não se problematizam, por isso não avançam.

Tais informações podem apontar para uma cristalização e homogeneização do não aprender do aluno com deficiência intelectual da Educação Especial, ou para a solidificação do mito de que o aprender é próprio a um tipo de aluno ideal, que - é claro!... - se encontra longe dos alunos objeto desta pesquisa. Sobre isso, Patto (1990) nos traz que a escola ensina de acordo com modelos considerados adequados à aprendizagem de um aluno tido como intelectual e biologicamente ideal, e aqueles que não correspondem a tais ideais mostram ter problemas de aprendizagem em razão de suas disfunções psiconeurológicas. Uma análise nesse sentido exclui o complexo universo de questões institucionais, políticas e individuais componentes do cotidiano escolar que levam ao seu fracasso. É preciso contextualizar no âmbito de um processo maior a questão do desempenho escolar desses alunos, haja vista que é construída socialmente, e não apenas biologicamente.

Ao analisar tais questões, consideramos os ideais da sociedade, que classifica e valoriza alguém como bom aluno pelas suas condições emergenciais de corresponder aos requisitos de desenvolvimento "adequado" num tempo e espaço determinados.

Assim, refletimos sobre a necessidade de romper com preconceitos e estereótipos que contribuem para a crença de que as pessoas com deficiência intelectual são incapazes, ou mesmo que contêm em si seu próprio aniquilamento. É preciso considerar e fazer movimentar as possibilidades de desenvolvimento das funções psíquicas superiores dessas pessoas.

Em relação às informações categorizadas, identificamos que a compreensão das participantes acerca da queixa escolar nas escolas especiais pesquisadas está geralmente relacionada ao aluno, às dificuldades que este apresenta quanto à sua aprendizagem, bem como às alterações de comportamento. Referem-se à falta de avanço desses educandos em seu aprendizado, a estes não conseguirem acompanhar, a não reterem e registrarem os conteúdos, a estar comprometido seu processo de leitura e escrita, às dificuldades generalizadas, acentuadas e ao mesmo tempo específicas de cada aluno.

Tais evidências estão expressas nas seguintes categorias: Dificuldade específica que o aluno tem (18,5\%); Aluno que tem mais dificuldades em assimilar, reter e/ou registrar os conhecimentos e/ou em fazer elaborações mais complexas (14,9\%); Quando se trabalha com os alunos e não se obtêm resultados (7,4\%); Dificuldade de aprendizagem decorrente do comportamento inadequado da criança $(7,4 \%)$.

Sob esta lógica, centra-se no indivíduo toda a problemática escolar, como se fosse possível explicar os fracassos a partir das próprias características, desmembrando-se o individual do social. Desse modo, é consolidada a crença de que o sucesso ou o fracasso individual são consequência direta das diferenças individuais (Patto, 1990), as quais afloram principalmente quando estamos diante do ensino de conteúdos que não fazem sentido para o aluno, mas cuja não aprendizagem é tomada como incapacidade deste para deles se apropriar.

Dentro dessa tendência a individualizar as relações de ensino-aprendizagem, Padilha (1994) explica que a queixa escolar surge na medida em que as crianças não correspondem às expectativas de aprendizagem da escola, levando a várias possibilidades de explicação, embora muitas vezes essas possibilidades se reduzam a teorias que cingem o processo escolar ao aluno que não está aprendendo, deixando de considerar os fatores intraescolares e o conjunto de relações que constituem o cotidiano escolar.

Em sentido contrário a essas explicações centradas nas pessoas específicas, Vygotski (1997) considera que é nas relações sociais estabelecidas pelo indivíduo com o mundo exterior que têm origem as formas superiores de comportamento, de modo que sua existência e desenvolvimento se concretizam nas relações sociais. Com isso, não é possível as explicações das dificuldades de aprendizagem de uma criança "caberem" dentro dela mesma.

Não se trata de negar a relação entre o fato de o aluno vivenciar seus aspectos biológicos e as dificuldades que ele encontra em acompanhar o aprendizado, mas sim de considerar que as relações escolares contribuem para modificar esses aspectos, recriando as possibilidades e limitações trazidas ou construídas nesse complexo processo da vida diária da escola (Proença, 2004); no entanto, como esclarece Saviani (2009, p. 227), “(...) é preciso levar em conta que só se transforma alguma coisa a partir das condições existentes".

Por outro lado, na reflexão sobre as categorias, pudemos encontrar nas escolas, reveladas nos questionamentos, preocupações das educadoras que ultrapassam a instância de aluno-problema e avaliam os fatores intraescolares que interferem na questão (11,1\%). Assim, é importante também considerar as categorias: Dificuldade de aprendizagem associada à prática pedagógica $(7,4 \%)$ e Dificuldade de aprendizagem em decorrência de uma falha no processo de escolarização (3,7\%). Desse modo, refletimos sobre o papel 
Tabela 2. Possíveis causas da queixa escolar.

\begin{tabular}{l|l|l|l|l|l|l|l|l}
\hline Categorias & \multicolumn{2}{|c|}{ G1 } & \multicolumn{2}{c|}{ G2 } & \multicolumn{2}{c|}{ G3 } & \multicolumn{3}{c}{ Total } \\
\hline & F & $\%$ & F & $\%$ & F & $\%$ & F & $\%$ \\
\hline 1-O aluno & 12 & 41.4 & 8 & 38.1 & 4 & 25 & 24 & 36.1 \\
\hline 2-Deficiência intelectual & 7 & 24.1 & 6 & 28.6 & 4 & 25 & 17 & 26 \\
\hline 3-A família & 7 & 24.2 & 5 & 23.8 & 4 & 25 & 16 & 24.2 \\
\hline 4-Fatores socioeconômicos & - & - & 2 & 9.5 & 2 & 12.5 & 4 & 6.1 \\
\hline 5- O professor & 1 & 3.4 & - & - & 2 & 12.5 & 3 & 4.6 \\
\hline $\begin{array}{l}\text { 6-Demora na identificação e no } \\
\text { encaminhamento }\end{array}$ & 2 & 6.9 & - & - & - & - & 2 & 3 \\
\hline Total & & & & & & & & 100 \\
\hline
\end{tabular}

Nota: As porcentagens foram calculadas a partir do total de respostas referentes às distintas categorias e não a partir do número de participantes.

do educador e sobre o trabalho por ele realizado, bem como sobre as relações estabelecidas dentro do âmbito escolar, elementos que representam a necessidade de apreensão de outras referências, além de incutirem no aluno as evidências de "sua" não aprendizagem.

Quanto à sua relevância, essas respostas vêm ao encontro dos teóricos Vygotsky e Luria (1996), os quais enfatizam o papel do educador, que, ao agir como mediador, atua na zona de desenvolvimento proximal, ou seja, ele parte do que a criança já conhece e oferece condições para que ela alcance um nível de desenvolvimento mais autônomo e passe a desenvolver habilidades humanas específicas, as funções psicológicas superiores, já que a aprendizagem é um aspecto necessário e universal do processo de desenvolvimento dessas funções.

Nessa perspectiva, dada a importância do ensino para o desenvolvimento da pessoa com deficiência intelectual e para formação e desenvolvimento de suas potencialidades, é mister considerarmos a qualidade das mediações no trabalho com elas realizado, fazendo desse modo o transporte do olhar da "deficiência do aluno" para a possibilidade de "deficiência do ensino".

Por outro lado, quando as entrevistadas colocam a questão da técnica de ensino do educador articulada às dificuldades de aprendizagem de seus alunos, elas já não situam o foco nos seus problemas individuais, mas estão levando em conta a escola na produção da queixa escolar, ainda que sob o risco de se limitar a uma escola abstrata, ou seja, desvinculada da sociedade em que se insere. De acordo com Angelucci, Kalmus, Paparelli e Patto (2004), desse modo continuamos a compreender a queixa escolar como resultado de variáveis individuais, mudando apenas o ator social e mantendo o mesmo cenário. Então a questão deve ser cuidadosamente avaliada, para não realizarmos apenas um deslocamento de culpabilizações.
Por fim, salientamos que a compreensão da queixa escolar requisita a articulação das relações da história pessoal com a história escolar da criança, constituídas num contexto histórico-cultural e econômico-social.

\section{Possíveis causas da queixa escolar}

Ao analisarmos a tabela 2 , verificamos que as informações nela contidas apontam que a maioria das respostas se relaciona a aspectos individuais. Tais aspectos ora são elencados na pessoa com deficiência (no seu orgânico, na má alimentação, na deficiência intelectual, na sua saúde, no seu interesse, no seu comportamento, nas suas inúmeras faltas e falhas), ora na família (por não estimular em casa etc.), ora no professor (por não utilizar as metodologias adequadas). Essas informações (centradas no sujeito, em suas características ou ações específicas) são condizentes com as das categorias da tabela 1, quando as participantes revelam a sua compreensão sobre a queixa escolar, desconsiderando a dimensão da totalidade e as relações existentes dentro e fora do contexto escolar. Essa culpabilização e generalização estão muito presentes em seus relatos, como pode ser observada na seguinte fala: "[...] eu acho que é um problema deles mesmo, né, cognitivo, o grau de comprometimento, e o histórico familiar. É difícil, né, eles vêm tem dias para escola e não tão bem, estão com problemas em casa, aí você vai tentar conversar [...]" (P6/G2).

Neste momento consideramos importante retomarmos as considerações de Patto (1997) sobre a produção do fracasso escolar, ao expor que a partir de uma abordagem psicologista a explicação para este está vinculada às diferenças e méritos individuais, à capacidade orgânica de aprender dos alunos, a aspectos neurológicos, à deficiência intelectual etc. Desse modo, produz-se uma depreciação da 
capacidade cognitiva, mascarando uma compreensão social mais ampla do fracasso escolar. Não há a compreensão de que os problemas escolares estão intrinsecamente relacionados com a sociedade e de que é necessário rever a educação por esta promovida, a qual serve às ideologias presentes em nossa sociedade de classes. Uma concepção diferenciada deveria fornecer uma visão não dicotômica do homem e da sociedade.

Foi possível encontrar nas respostas das participantes agrupadas na categoria Aluno (36,1\%), explicações causais que fazem referência ao biológico, a problemas relacionados com a saúde, com a alimentação. Nesse prisma, recorremos a Pessoti (1984), o qual, em seus estudos, verificou que o enfoque organicista esteve (neste caso podemos verificar que ainda está) fortemente presente na história da evolução do conceito de deficiência intelectual, ocorrendo o que o autor denomina de ditadura médica. É importante rompermos com a postura organicista no que tange ao seu fatalismo. Não concordamos em legitimar qualquer distúrbio no aluno antes de verificar como está ocorrendo sua experiência escolar; e mesmo que sejam encontradas deficiências neste aluno, a totalidade da complexidade envolvida nas relações escolares de ensino-aprendizagem deve ser considerada e, inversamente, não restrita a um inadequado biológico.

Diante dos relatos das participantes percebemos uma valorização do biológico em detrimento do social como principal fator do desenvolvimento da pessoa com deficiência. De fato, o biológico não deixa de ser importante neste caso das pessoas com deficiência intelectual, pois, de acordo com Vigotski (1996), no início da vida os fatores biológicos desempenham um papel mais marcante; no entanto, à medida que a criança intensifica suas relações com o mundo, a cultura passa a ser o elemento decisivo na definição dos rumos do desenvolvimento. Assim, a apropriação cultural torna-se o principal mecanismo determinante do desenvolvimento do psiquismo humano, pois este se forma no decurso da vida.

Merece destaque o fato de a categoria Família ter uma significativa representatividade $(24,2 \%)$ na explicação das queixas escolares. Assim, são mencionados pelas educadoras a falta de estimulação e de interesse, o não acompanhamento das tarefas escolares e as limitações e dificuldades para fazê-lo, a não aceitação da deficiência e a grande expectativa em relação ao aprendizado dos filhos. Elas referem, enfim, que essas questões familiares são explicativas e responsabilizáveis pela não aprendizagem dos seus alunos. Desse modo, visões simplistas, unilaterais e até contraditórias são expressas, ou seja, os familiares são culpados por terem expectativas positivas, por quererem ver seu filho se desenvolver e, ao mesmo tempo, por não se interessarem por seu desenvolvimento. É claro que não podemos deixar de mencionar a importância de uma parceria com a família, no sentido de que esta possa compreender os processos de aprendizagem escolar pelos quais estão passando seus filhos.

Quando nos reportamos às famílias desses alunos, estamos falando também de ideais de família no que tange a sua estrutura e organização e sua condição histórica e so- cioeconômica, e ao mesmo tempo revelando as realidades familiares contextualizadas numa sociedade de classes que prima pelo mérito individual e impõe às famílias explicações que seriam históricas, culturais e econômicas.

Em referência à atribuição a causas individuais de problemas que envolvem uma complexa rede, podemos fazer alusão a Bray (2009), cujo estudo acerca das queixas escolares em escolas regulares públicas e privadas no interior do Paraná verificou que cerca de $90 \%$ das respostas dos educadores sobre as causas das dificuldades de aprendizagem dos alunos diziam respeito a esse processo de culpabilização e explicação reduzidas ao indivíduo (ao aluno e à sua família).

Assim, nas duas realidades de ensino (especial e regular) são ocultadas reflexões críticas referentes ao que ocorre nas relações produzidas no interior das escolas. Evidencia-se ainda que tais instituições escolares, inseridas numa mesma sociedade, revelam gratuitamente sua comunhão com os preceitos da ideologia neoliberal, requerendo a adequação do indivíduo à sociedade e às suas demandas, e a sua consequente culpabilização pelo insucesso ao não consegui-lo "adequada e normalmente". Meira (2003) acrescenta que isso reflete o processo de psicologização e patologização dos problemas educacionais.

Assim, essa tendência ideológica de tentar descontextualizar a dificuldade de aprendizagem da esfera escolar e social vem ao encontro do que expressa um dos participantes: "[...]Eu não vejo [...] que a maioria dos casos que eu tenho é por algum comprometimento, por uma questão pedagógica, nem um caso que eu tenha, porque a gente sabe que dentro das escolas de ensino regular a gente tem vários casos de problema de origem pedagógica. Aqui eu não classifico como isso" (P2/G2).

Se o caso dos alunos das escolas especiais não tem relação com o pedagógico, então por que eles frequentam uma escola e por que nesta é preciso que trabalhem professores especializados? Estamos, então, diante de instituições cuidadoras, e não de instituições educadoras, por causa do comprometimento biológico de seus alunos? Amaral (1998) nos encaminha a considerar que estamos diante de uma generalização indevida, em que os alunos com deficiência intelectual são reduzidos à sua condição de ineficiência.

Compreendemos essa necessidade das educadoras de tentar visualizar o aluno em sua totalidade, atualmente tão difundida como importante, porém não podemos limitar-nos àquelas características encarceradas na sua pessoa, sem deixar de considerar os processos e as relações produzidas com estas faltas e as possibilidades que estão além delas. Tais relações podem ter como palco uma sociedade ou uma escola (nos seus diferentes componentes) que vivencia com seus integrantes ou alunos o entorno da passividade e em que o não aprendizado dos conteúdos científicos é muitas vezes uma realidade com a qual ela se conforma.

Não podemos perder de vista que o sucesso escolar do aluno está relacionado a diversos fatores e que ele é possível na medida em que o consideremos para além de sua aparência e, mais do que isso, quando construímos ações 
coletivas na busca pela superação do descrédito da diferença, do processo de exclusão e das contradições a que estão submetidas estas pessoas.

\section{Considerações finais}

Os resultados obtidos apontam que entre as educadoras prevalece a concepção de queixa escolar que centraliza no aluno toda a problemática vivenciada no contexto da escola, pelo "seu" não aprendizado acadêmico. Pudemos evidenciar tais informações também no item referente às possíveis causas da queixa escolar, pois a maioria das respostas é atribuída ao indivíduo e diluída nas suas deficiências, seja em relação ao seu cognitivo, à sua saúde ou ao seu interesse. No tocante ao educador, elas estão relacionadas às metodologias e à sua formação. As justificativas pelo não aprendizado escolar do aluno são também encontradas na família, por sua falta de estimulação e interesse pela escolarização do filho/aluno.

Uma questão muito importante apontada nos resultados envolve o fato de as dificuldades vivenciadas pelos alunos no processo de aprendizagem não serem tidas como um problema diferenciado que possa se apresentar num determinado momento, ou como uma queixa escolar, mas como algo já naturalizado, comum no cotidiano escolar da Educação Especial. Assim, a queixa não é vislumbrada como tal, mas como uma práxis da educação escolar com deficientes intelectuais, "um caminho sem volta".

A realidade encontrada nas explicações das educadoras, restritas à limitação dos alunos e inteiramente devidas à deficiência, desconsiderando-se na maioria das vezes a questão pedagógica, remete-nos a algumas dúvidas, entre elas a importância dada ao trabalho pelo próprio educador, que muitas vezes se contradiz na ambiguidade educar $x$ assistir, pois ao mesmo tempo em que busca a aprendizagem, também a desconsidera, seja ao se referir à incapacidade de seus alunos por conta do biológico, seja quando não leva em conta o importante processo de ensinar. Como bem expressou Vygotski (2000), o todo da criança é mais do que o simples agrupamento de suas partes, de qualidades peculiares. Não podemos deixar de visualizar esse todo em movimento e as possibilidades que vão sendo criadas à medida que esse aluno se relaciona com o outro.

Assim, salientamos que, se permanecermos acreditando na impossibilidade de o aluno com deficiência intelectual aprender por causa de suas peculiaridades, esse aluno certamente continuará por muito tempo submetido à exclusão do saber produzido ao longo das gerações. Tal posicionamento, por outro lado, não nega que existam dificuldades, sendo elas variadas e contextualizadas; no entanto, à medida que nos guiamos unicamente pela incapacidade e limitação dessas pessoas como fatores determinantes, negativos e irreversíveis, estamos fortalecendo os processos de sua exclusão.

Um trabalho educativo numa vertente contrária a isso considera que o processo de ensino-aprendizagem deve ser de desafios, de provocações ao desenvolvimento das funções psicológicas superiores, e não de simples adequação e conformismo com sua apresentação. Desse modo, diante do desenvolvimento do aluno com deficiência, devemos conduzi-lo, por objetivos e exigências sociais, para fora de um mundo de segregação, de negação.

Para que o educador tenha condições de compreender e romper com a trama de ideais e de alienação a que estamos submetidos, deve ser-lhe oportunizado refletir sobre a conexão da sua subjetividade com a realidade social, numa consideração às dimensões políticas e ideológicas do seu trabalho.

Temos, assim, "pistas" para a questão elucidada neste artigo no que tange à possibilidade de existência do fracasso escolar na Educação Especial. Neste caso, temos revelada a sua "não existência", ou seja, o que existe nestas instituições (de acordo com as concepções das educadoras) são alunos que não sofrem o fracasso escolar, na medida em que sofrem de uma deficiência que por si só os anula. As educadoras excluem-se das práticas e das relações que realizam com esses alunos e dessa maneira desvalorizam o próprio trabalho que fazem com eles.

Nesse aspecto a Psicologia Histórico-Cultural, fundamentada e exercitada no Materialismo Histórico-Dialético, é essencial por permitir esse olhar multifacetado sobre as relações produzidas no tocante aos diversos fenômenos humanos, por tornar possível olhar para o homem concreto, com deficiência ou não, considerando-o dentro das contradições que o recriam, dentro do sistema que salienta sua individualidade eficiente ou deficiente.

Defendemos que uma análise ampla do contexto escolar e das múltiplas determinações que acarretam a queixa, tratadas na Educação Especial ou numa educação que se pretenda inclusiva e valorize o sucesso escolar, deve vislumbrar as possibilidades dos seus alunos, a fim de que suas intelectualidades saiam do plano da invisibilidade, da negatividade, movimentando assim impossibilidades cristalizadas ao redor de naturalizações preconcebidas de desenvolvimento humano. Nesse prisma faz-se importante que outras pesquisas sejam desenvolvidas, que venham a colaborar para a superação das concepções biologizantes que ainda alicerçam o trabalho de muitos educadores na Educação Especial.

\section{Referências}

Amaral, L. A. (1998). Deficiência, questões conceituais e alguns de seus desdobramentos. Cadernos de Psicologia, 3(1). Recuperado: 28 set. 2009. Disponível: www.fop.unicamp. br/...103_9_Deficiencia_Questoes_conceituais.pdf

Angelucci, C. B., Kalmus, J., Paparelli, R., \& Patto, M. H. S. (2004). O estado da arte da pesquisa sobre o fracasso escolar (1991-2002): um estudo introdutório. Educação e Pesquisa, 30(1). Recuperado: 20 jun. 2008. Disponível: http://www.scielo.br/scielo. php?script=sci_arttext\&pid=S151797022004000100004 
Bray, C. T. (2009). Queixas escolares na perspectiva de educadores das redes pública e privada: contribuição da psicologia históricocultural. Dissertação de Mestrado, Programa de Pós-Graduação em Psicologia, Universidade Estadual de Maringá, Maringá, Paraná.

Laplane, A. (2006). Uma análise das condições para a implementação de políticas de educação. Revista Educ. Soc., 27(96), 689-715. Recuperado: 02 jun. 2008. Disponível: http://www.cedes.unicamp.br

Machado, A. M. (1997). Avaliação e fracasso: a produção coletiva da queixa escolar. Em J. G. Aquino (Org.), Erro e fracasso na escola: alternativas teóricas (pp.73-90). São Paulo: Summus.

Meira, M. E. M. (2003). Construindo uma concepção crítica de psicologia escolar: contribuições da pedagogia histórico-crítica e da psicologia sócio-histórica. Em M. E. M. Meira \& M. A. M. Antunes (Orgs.), Psicologia Escolar: teorias críticas (pp. 13-78). São Paulo: Casa do Psicólogo.

Padilha, A. M. L. (1994). Possibilidades de histórias ao contrário ou como desencaminhar o aluno da classe especial. São Paulo: Plexus.

Patto, M. H. S. (1990). A produção do fracasso escolar: histórias de submissão e rebeldia. São Paulo: T. A. Queiroz.

Patto, M. H. S. (1997). Para uma crítica da razão psicométrica. Revista Psicologia USP, 8(1), 47-62.

Pessoti, I. (1984). Deficiência mental: da superstição à ciência. São Paulo: T.A. Queiroz.

Proença, M. (2004). A queixa escolar e o predomínio de uma visão de mundo. Em A. M. Machado \& M. Proença (Orgs.), Psicologia escolar em busca de novos rumos (pp. 19-38). São Paulo: Casa do Psicólogo.
Rocha, D., \& Deusdará, B. (2005). Análise de Conteúdo e Análise do Discurso: aproximações e afastamentos na (re) construção de uma trajetória. Alea - Estudos Neolatinos, 7(2). Recuperado: 27 jun. 2008. Disponível: http://www.scielo.br/scielo.php?pid

Saviani, D. (2005). Sobre a natureza e a especificidade da educação escolar. Em D. Saviani, Pedagogia Histórico-Crítica: primeiras aproximações (9a ed., pp.11-22). Campinas, SP: Cortez-Autores Associados.

Saviani, D. (2009). Educação brasileira contemporânea: obstáculos, impasses e superação. Em D. Saviani, Educação: do senso comum à consciência filosófica (18a ed., pp. 209-244). Campinas, SP: Autores Associados.

Vigotski, L. S. (1996). O significado histórico da crise da psicologia: uma investigação metodológica. Em L. S. Vigotski, Teoria e método em Psicologia (pp. 203-420). São Paulo: Editora Martins Fontes.

Vygotski, L. S. (1997). Fundamentos de defectología. Em Obras escogidas (Tomo V) Madrid: Visor Distribuciones. (Trabalho original publicado em 1983)

Vygotski, L. S. (2000). Problemas del desarrollo de la psique. Em Obras escogidas (Tomo III). Madrid: Visor Distribuciones. (Trabalho original publicado em 1983)

Vygotsky, L. S., \& Luria A. R. (1996). A criança e seu comportamento. Em L. S. Vygotsky \& A. R. Luria, Estudos sobre a história do comportamento: símios homem primitivo e criança (pp.151-239). Porto Alegre: Artes Médicas.

\section{Sobre as autoras}

Solange Pereira Marques Rossato (solmarques@hotmail.com)

Mestre em Psicologia pela Universidade Estadual de Maringá; Endereço: Rua Paranaguá, 565, bloco 02, apto 01, Zona Sete, CEP: 87020-190, Maringá - PR;

Nilza Sanches Tessaro Leonardo (nstessaro@uem.br)

Doutora em Psicologia; Docente da Universidade Estadual de Maringá; Departamento de Psicologia; Endereço: PPI - UEM - Avenida Colombo $n^{\circ}$ 5790, bloco 118, CEP: 87020-900, Zona Sete, Maringá - PR.

Trabalho derivado de parte da dissertação de mestrado de Solange Pereira Marques Rossato, intitulada de Queixa escolar e Educação Especial: intelectualidades invisíveis, defendida em 2010, sob orientação da professora doutora Nilza Sanches Tessaro Leonardo. Vale esclarecer que a mestranda recebeu apoio financeiro pela Capes, e o projeto desta pesquisa foi submetido ao Comitê de Ética envolvendo Seres Humanos, após o consentimento dos diretores (e antes da realização das entrevistas). Deste modo, os dados foram trabalhados e analisados de forma a manter o anonimato, o sigilo sobre a identidade das participantes, bem como do estabelecimento e da cidade em que a pesquisa foi realizada. 